\title{
Larval nutrition-induced plasticity affects reproduction and gene expression of the ladybeetle, Cryptolaemus montrouzieri
}

\author{
Jiaqin Xie ${ }^{1,2}$, Patrick De Clercq ${ }^{2 *}$, Chang Pan ${ }^{1}$, Haosen $\mathrm{Li}^{1}$, Yuhong Zhang ${ }^{3}$ and Hong Pang ${ }^{1 *}$
}

\begin{abstract}
Background: Organisms may develop into multiple phenotypes under different nutritional environments by developmental plasticity, whereas the potential costs and mechanisms of such plasticity are poorly understood. Here we examined the fitness and gene expression of nutrition-induced phenotypes in the ladybeetle, Cryptolaemus montrouzieri after having experienced varying larval food regimes.
\end{abstract}

Results: We found that C. montrouzieri adults undergoing a variable larval food regime achieved a similar developmental time, survival, body mass and egg production as those undergoing a high larval food regime. The survival, developmental time, body mass and fecundity of the adults from a restricted larval food regime were inferior to those from the high and variable larval food regimes. However, the adults from this restricted larval food regime had a higher expression level of genes encoding immune- and antioxidant-related enzymes than those from the high and variable larval food regimes when exposed to starvation and pesticide conditions in adult life.

Conclusions: These results suggest that larval food availability in C. montrouzieri not only triggers adult phenotypic differences but also affects reproduction and expression level of genes in adult life, indicating that the larval nutritional conditions can affect adult fitness and resistance to stressful conditions through developmental plasticity.

Keywords: Food availability, Cryptolaemus montrouzieri, Developmental plasticity, Fitness, Gene expression

\section{Background}

Developmental plasticity is an adaptive process that gives rise to multiple phenotypes under different environmental conditions [1-3]. Many factors may affect this process, including biotic (i.e. parasites, pathogens) and abiotic cues (temperature, humidity and photoperiod) [2, 4-6]. Organismal phenotypes adaptably vary in response to external environments, resulting in changes in body size, color or wing pattern [7-9]. Although the environment-induced traits are generally phenotypic variations that do not involve mutation or changes in DNA sequence, the plasticity plays crucial role in

\footnotetext{
* Correspondence: Patrick.DeClercq@UGent.be; Isshpang@mail.sysu.edu.cn ${ }^{2}$ Department of Crop Protection, Faculty of Bioscience Engineering, Ghent University, Ghent B-9000, Belgium

'State Key Laboratory of Biocontrol, Key Laboratory of Biodiversity Dynamics and Conservation of Guangdong Higher Education Institute, College of Ecology and Evolution, Sun Yat-sen University, Guangzhou 510275, China Full list of author information is available at the end of the article
}

maintaining the adaptability of individuals to potential environmental fluctuations $[1,6,10]$. For example, the nutrition-induced horn dimorphism of male Onthophagus taurus scarabs enhances their mating success and reproduction under certain external conditions [11]; the larval diet regime is associated with the caste of honeybees [12]. Furthermore, studies have reported that under certain conditions, the environment-induced phenotypes are genetically fixed through genetic assimilation, suggesting that developmental plasticity may accelerate adaptive evolution [13].

To better match the phenotypes and selective environments, organisms adapt to the environmental conditions under which they live in by altering their behavior, physiology or morphology. The environmental conditions organisms experienced in their early life stages predict what conditions they will encounter in later life and allow them to adapt to such conditions by developmental plasticity $[2,14]$. For instance, the nutrition-induced wing 
formation in the female pea aphid, Acyrthosiphon pisum, affects its dispersal in adult life [9]. However, the mechanisms of nutrition-induced developmental plasticity remain elusive $[1,15,16]$. A few studies report that hormones and DNA methylation affect the differentiation of adult phenotypes by regulating gene expression [17, 18]. More recently, it has been reported that cells also adapt their phenotypes by sensing the environmental conditions through a cell-intrinsic molecular mechanism by activating focal adhesion kinase (FAK, also known as PTK2), resulting in the adaptation of genes controlling membrane homeostasis [19]. Those studies have shed first light onto the molecular mechanism of developmental plasticity in response to external environments.

Larval nutritional conditions may affect adult reproductive performance and physiological functions in insects (e.g. metabolism, immune and antioxidant activities) [4, 20-24]. Whereas developmental plasticity has been noted to allow individuals to better respond to varying environmental conditions, less attention has been paid to the potential challenges of such plasticity on the fitness of the resulting phenotypes and to the effects on the expression levels of genes. In the present study, we examined the development, reproduction and gene expression of adults that experienced varying larval food regimes in the ladybeetle $C$. montrouzieri. The ladybeetle originates from Australia and has been introduced into at least 64 countries or regions around the world as a biological control agent $[25,26]$. Its growth rate and phenotypes are largely nutrition-dependent, which makes the ladybeetle a suitable model to study nutrition-induced developmental plasticity and its effects on the fitness of the resulting phenotypes $[21,26]$.

We manipulated the food availability of the ladybeetle during its larval stages. C. montrouzieri larvae were subjected to high, variable and low food regimes, allowing them to grow at a normal, variable and restricted rate, respectively. Upon adult emergence, we examined the body mass, developmental time and survival of the ladybeetles from the different larval treatments. We then examined their reproductive performance (pre-oviposition period, fecundity, egg hatch) under an ad libitum food regime. Subsequently, we assessed the expression level of genes encoding immune- and antioxidant-related enzymes in adults under stressful conditions (i.e. starvation and pesticide exposure) using $\mathrm{qPCR}$, and evaluated the starvation resistance of the adults from each larval food regime. The hypothesis was that if C. montrouzieri plastically developed in response to varying larval food regimes, their growth rate and adult phenotypes might be different. The resulting phenotypes from varying larval food regimes were expected to display different adult traits (e.g. reproductive output or gene expression).

\section{Methods}

\section{Insect cultures}

C. montrouzieri used in the experiments were obtained from a laboratory culture at Sun Yat-sen University, Guangzhou, China. The ladybeetles were reared on citrus mealybugs, Planococcus citri maintained on pumpkin fruits at ambient conditions $\left(\mathrm{T}=25 \pm 1{ }^{\circ} \mathrm{C}, \mathrm{RH}=60 \pm 10 \%\right)$. Prior to the experiments, 50 pairs of females and males were randomly collected from the stock culture and placed in individual Petri dishes $(90 \mathrm{~mm} \times 15 \mathrm{~mm})$ to oviposit. We used cotton as an oviposition substrate and collected eggs from the third to seventh day of adult life. The eggs were allowed to hatch in a climate chamber at $25 \pm 1{ }^{\circ} \mathrm{C}, 70 \pm 5 \% \mathrm{RH}$ and a 14:10 h (L:D) photoperiod. Four days later, the emerging larvae were used in the experiment.

\section{Developmental plasticity}

Newly hatched $(<12$ h) larvae of $C$. montrouzieri were transferred to Petri dish arenas $(90 \mathrm{~mm} \times 15 \mathrm{~mm})$ and subjected to one of the three food regimes $(n=95,95$ and 105 for high, variable and restricted larval food regimes, respectively), simulating natural conditions of food abundance, variation in food supply and food scarcity. First and second instars of C. montrouzieri were maintained in groups of ten in each Petri dish; from the third instar on, each predator larva was isolated in an individual Petri dish. In the high food regime, ten $P$. citri (ca. $1.5 \mathrm{~mm}$ long) were supplied to each Petri dish and refreshed daily, allowing the ladybeetle to grow at normal rate. In the variable food regime, five $P$. citri larvae were supplied to each Petri dish and replaced every $48 \mathrm{~h}$ during the first eight days; from the ninth day on, food was supplied to the larvae in the same manner as in the high level food regime, allowing the individuals to experience compensatory growth [21]. Finally, in the low food regime, five $P$. citri larvae were supplied in each Petri dish and replaced every $48 \mathrm{~h}$ until the emergence of the adult ladybeetle, resulting in a restricted growth pattern. Thus, developmental plasticity yielded different phenotypes (i.e. restricted, compensatory and normal growth phenotypes) in response to varying larval food regimes. We assessed adult body mass within 48 h of adult emergence ( $n=15$ for each sex) using an electronic balance (Sartorius BSA124S, Germany, $\pm 0.1 \mathrm{mg}$ ). We also calculated the developmental time (from egg hatch to adult emergence) and survival rate of each group (the number of emerged adults out of the number of hatched larvae in each group).

\section{Reproductive performance}

To examine the reproductive performance of the different resulting phenotypes, the emerging adult males and females from the same group were randomly paired $(n=15)$ and supplied ad libitum with $P$. citri from adult emergence. 
Each pair was placed in an individual $90 \mathrm{~mm}$ diameter Petri dish and maintained in a climate chamber set at $25 \pm 1{ }^{\circ} \mathrm{C}, 70 \pm 5 \% \mathrm{RH}$ and a $14: 10 \mathrm{~h}$ (L:D) photoperiod. Their foods were refreshed and eggs were collected daily. The pre-oviposition period (from the time of pairing to first oviposition) was determined, and the numbers of deposited and hatched eggs were recorded within one month.

\section{Starvation resistance}

Upon adult emergence, we evaluated the starvation resistance of the resulting adult phenotypes of $C$. montrouzieri. We examined the body mass change of female adults from the three larval treatments when experiencing a starvation period of five days (i.e. without food and water) versus ad libitum feeding on $P$. citri. First the initial body mass of the emerging female adults was recorded. Then, the females were placed into individual Petri dishes and exposed to the starvation or ad libitum food treatment in a climatic chamber at $25 \pm 1{ }^{\circ} \mathrm{C}, 70 \pm 5 \%$ $\mathrm{RH}$ and a 14:10 h (L:D) photoperiod $(\mathrm{n}=15)$. After 5 days, the final body mass of the adults was determined, and the mass change $(\Delta \mathrm{M})$ was calculated as (initial mass-final mass)/initial mass (\%). Further, we randomly collected ten (five for each sex) C. montrouzieri adults from each larval food regime on the tenth day, i.e. when they were reproductively active, to assess their starvation resistance. For this purpose, the beetles were placed in individual Petri dishes and deprived of food and water at $25 \pm 1{ }^{\circ} \mathrm{C}$, $70 \pm 5 \% \mathrm{RH}$ and a 14:10 h (L:D) photoperiod. Survival was monitored daily until all of the individuals had died.

\section{Gene expression}

To evaluate the gene expression in the adult female resulting phenotypes of $C$. montrouzieri, quantitative real-time PCR (qPCR) was performed to estimate the expression of genes (i.e. lysozyme, acid phosphatase, phenol oxidase, peroxidase, HSP60 and carboxylesterase) under two types of stress conditions: (1) starvation for $24 \mathrm{~h},(2)$ exposure to $4 \mathrm{ul}$ of the insecticide acetamiprid (16 ppm; Guoguang Agrochemical Co., Ltd, Sichuan, China) applied on the females' pronotum using a micropipette. The selected enzymes have important functions in immune or antioxidant activities [27, 28]. Food scarcity has been reported to affect individual physiological functions, but less attention has been paid to the expression level of genes. Acetamiprid is a commonly used insecticide in agriculture and has previously been reported to be harmful to $C$. montrouzieri [29]. All adult females used in the experiment were randomly collected from the different phenotype groups on the tenth day of adult life. The extraction of RNA, transcription and qPCR amplification were carried out according to standard procedures [20, 22, 30]. Briefly, total RNA of adults was extracted using Trizol Total
Isolation Kit (Invitrogen), and reverse transcription primed with oligo-dT was used to synthesize cDNA. Extractions of three individuals from each resulting phenotype after having undergone starvation or pesticide treatment were performed and two replicates of each extraction were used for qPCR. Relative transcript abundance was measured using $\mathrm{qPCR}$ on ABI STEPONE PLUS according to the manufacturer's protocols for SYBR Green (by BGI-Tech, Shenzhen, China). The tubulin beta (BT) gene was selected as the reference gene. The gene primers and sequences used in RT-qPCR amplification are given in Table 1.

\section{Statistical analysis}

Before analysis, all datasets were first tested for normality and homogeneity of variances by a Shapiro-Wilk test and Levene test, respectively. We used one-way analysis of variance (ANOVA) followed by Tukey tests to analyze the effect of larval food regimes (high, variable and low food regimes) on developmental time, adult body mass, egg hatch and body mass change. The egg production, preoviposition period and gene expression were tested using a Kruskal-Wallis test followed by Mann-Whitney $U$ test due to the lack of normal distribution of the data. The survival rate was compared by a logistic regression, which is a Generalized Linear Model using probit link and a binomial error function. The significance level of all tests was set at $p \leq 0.05$. All analyses were performed using SPSS 21 (IBM SPSS Statistical, Chicago, USA).

\section{Results}

\section{Developmental plasticity}

The developmental time and survival of the larval and pupal stages were significantly influenced by the larval

Table 1 Reference gene and gene sequences encoding immune and antioxidant enzymes used in $\mathrm{PPCR}$

\begin{tabular}{lll}
\hline Genes & Sequences (5'-3') & GenBank \\
\hline Lysozyme & F-TATTCCACGCGACCAGTTGG & KT358925 \\
& R-GGCGAGTCAGATTTGAGCA & \\
Acid phosphatase & F-TACCGGATGGACCCGTATG & KT363040 \\
& R-TCGTAGAACCGTCCCAAGGA & \\
Pro-phenol oxidase & F-AAGGAGGAGACGAACTGGCC & KT363041 \\
& R-CAATTGGCATGCAGTTCCTG & \\
Carboxylesterase & F-TCAAGGCCAGCTTCTGATGA & KT363042 \\
& R-GAAGAAGTGATCCGCGTCT & \\
Peroxidase & F-CAGCGAATCCCAGTTGGATG & KT363043 \\
& R-TGGCTTCGACACACGAGGT & \\
HSP60 & F-GCCGTCGAGGAAGGTATCGT & KT363038 \\
& R-ACACCGTTGCTTGATCCGA & \\
Tubulin beta & F-CTCCGACGAACATGGAATCG & ADI24738.1 \\
& R-TTGCCACCAGACGCTTCATT & \\
\hline
\end{tabular}


food regimes. Adult body mass of females and males from the restricted larval food regime was markedly lower than those of adults from the high and variable larval food regimes (females, $F_{2,42}=44.997, p<0.001$; males, $F_{2,} 42=21.273, p<0.001$; Fig. 1a), but adults from the variable food regime and high food regime had similar adult body weights (Tukey test, females, $p=0.684$; males, $p=0.502$; Fig. 1a). Further, the developmental time of the resulting phenotypes from

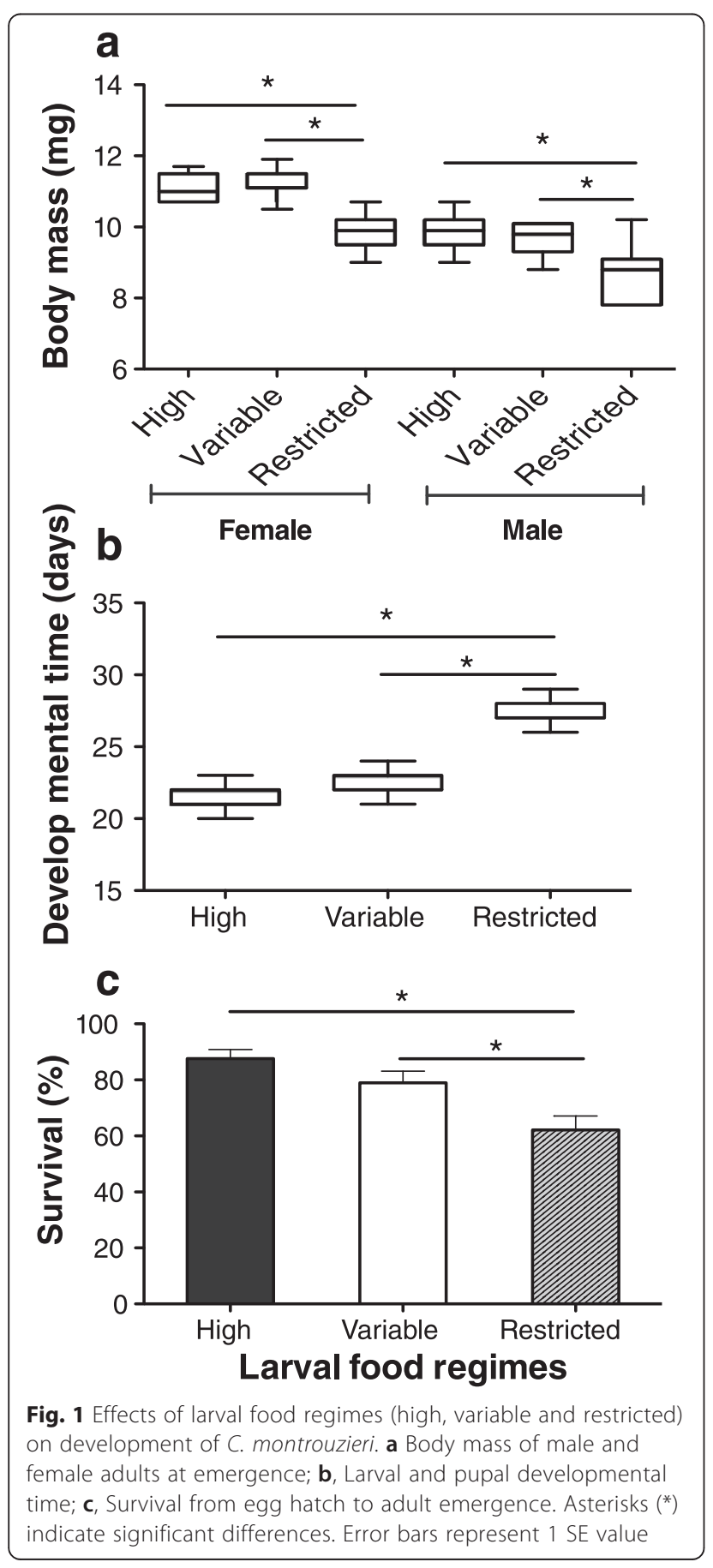

the restricted larval food regime was about five days longer than that of those from the variable and high larval food regimes $\left(F_{2,42}=191.950, p<0.001\right.$; Fig. $\left.1 b\right)$, with again no statistical difference between the latter two phenotypes (Tukey test, $p=0.106$; Fig. 1b). The survival of the resulting ladybeetles undergoing the restricted larval food regime was significantly lower than that of the other two phenotypes $\left(\chi^{2}=17.412, \mathrm{df}=2, p<0.001\right.$, Fig. $\left.1 \mathrm{c}\right)$.

\section{Reproductive performance}

Egg production of the resulting adult phenotypes was significantly affected by larval food regimes. Although there was no difference in pre-oviposition period when the adults of all groups were provided with ad libitum foods from emergence on (Kruskal-Wallis test, $p=0.319$; Fig. 2a), the egg production of the adult phenotypes from the restricted larval food regime was lower than that of adults from the high and variable larval food regimes (Kruskal-Wallis test, $p<0.001$; Fig. 2b). However, females from the variable larval food regime produced the similar egg numbers as those from the high larval food regime (Fig. 2b). In contrast, there was no difference in egg hatch among the three phenotypes $\left(\mathrm{F}_{2,42}=1.640, p=0.206\right.$; Fig. $\left.2 \mathrm{c}\right)$.

\section{Starvation resistance}

After experiencing a five-day period feeding on P. citri as larvae, the body mass increase of the females from the variable and high larval food regimes was lower than that of those which had experienced restricted food levels as larvae $\left(F_{2}, 45=52.894, p<0.001\right.$; Fig. $\left.3 \mathrm{a}\right)$. In contrast, no difference in body mass loss was observed among the treatment groups after female ladybeetles had experienced a five-day starvation period $\left(\mathrm{F}_{2,45}=2.373, p=0.106\right.$; Fig. 3a). Further, the starvation resistance of reproductively active adults in terms of their survival time when given no food or water conditions did not differ among the three treatment groups $\left(\mathrm{F}_{2,27}=2.443, p=0.106\right.$; Fig. 3b, c).

\section{Gene expression}

The gene expression of female adults subjected to starvation or acetamiprid treatment was associated with the food regime they experienced as larvae. In both treatments, the adults from the restricted larval food regime had a higher expression of the selected genes than those from the high and variable larval food regimes (Fig. 4). In the starvation, the gene expression of the resulting phenotypes that had experienced the variable larval food regime was lower as compared with its two counterparts (Fig. 4).

\section{Discussion}

Our findings indicate that the adult fitness of the ladybeetle C. montrouzieri is affected by larval nutritional conditions through developmental plasticity. The feeding regime of 


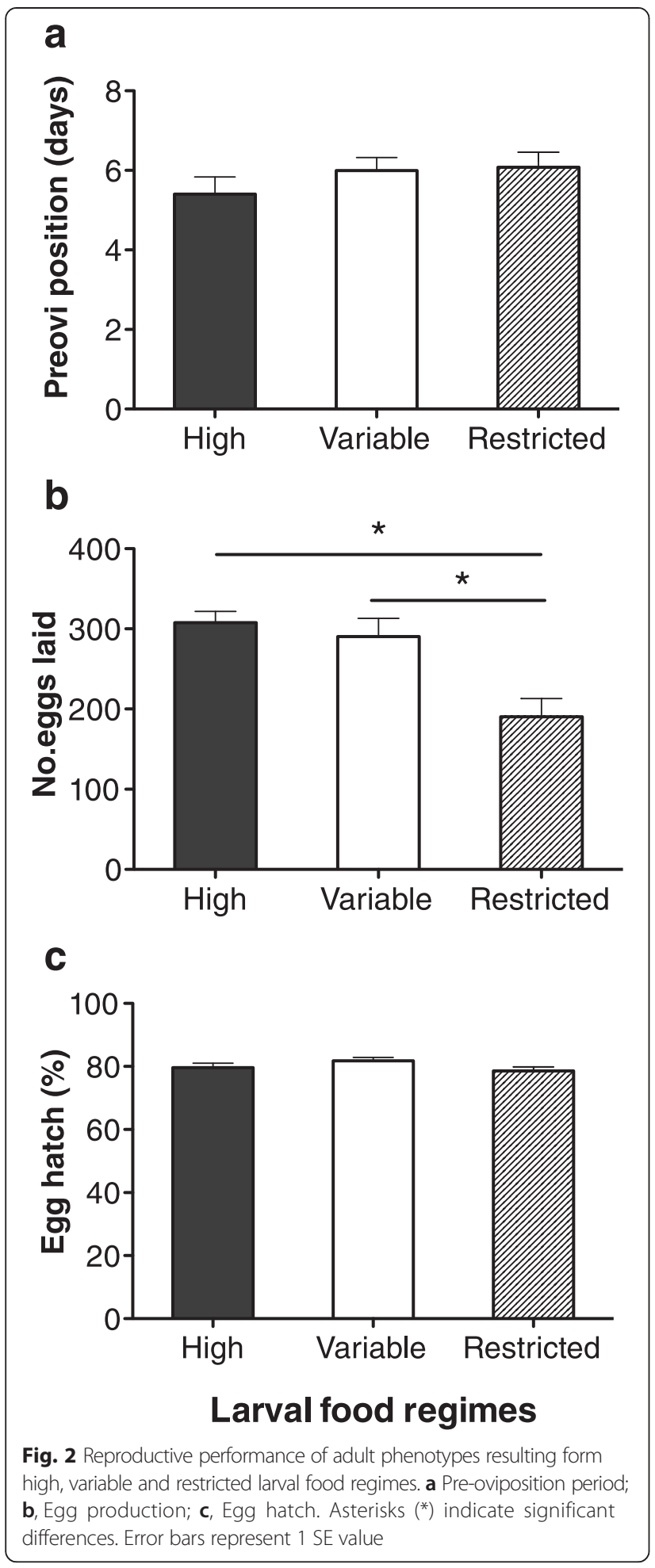

the larvae affected larval and pupal developmental time, with a longer time for insects experiencing the restricted larval food regime as compared with the variable or high larval food regimes, but with no difference between the latter two food regimes. The resulting adult phenotypes of
C. montrouzieri also had a different body mass and reproductive output, and showed different expression levels of genes under stressful conditions in adult life.

The environmental conditions experienced by organisms during early life can exert significant effects on development, reproduction and physiological functions [2, 4, 31]. Food availability is an important factor influencing individual developmental rate [4, 21, 32]. Generally, when individuals grow under favorable conditions (e.g., abundant food, lack of predators, optimal climate) they acquire a fast growth rate and suffer low mortality; conversely, individuals are expected to show reduced growth rates and high mortality under unfavorable environmental conditions (e.g., food scarcity, extreme temperature, high predator pressure) [24]. The responses shown by $C$. montrouzieri to the tested range of larval food regimes indeed suggest that food availability significantly affected individual growth. The beetles experiencing the high larval food regime had a faster development and higher survival than those from the restricted larval food regime (Fig. 1b). Additionally, we found that C. montrouzieri larvae subjected to the variable larval food regime had a similar survival rate as those from the high larval food regime, implying that food supplements in the late larval stage reduce the risk of mortality. Several studies have reported that compensatory growth, which takes place when food availability improves after a period of food scarcity, is a common strategy in insects to limit reduction in adult body size and reproduction $[4,32,33]$.

Various factors may affect individual reproductive performance including food availability and quality, mating success, population density and predation risks $[23,34,35]$. Among these factors, individual phenotypes (e.g., as characterized by body size) play an important role in determining reproduction [36]. Generally, in insects a large body size is associated with a high reproductive output, whereas small body size results in a low reproductive output under the same environmental conditions [32, 37, 38]. In our studies, we found that adults from the high larval food regime had greater body mass and higher egg production than those from the restricted food regime. Although ladybeetles from the variable larval food regime experienced nutritional restriction in the first eight days of larval development, they developed into adults with a similar body mass as those from high food regime, and had a similar egg production. This indicates that the compensatory growth took place in the later larval stages of $C$. montrouzieri after the switch in food supply, and that the larval nutritional conditions further affected adult fitness. Whereas previous studies have reported effects of body size on pre-oviposition period in other insect species $[39,40]$, no effects were found on pre-oviposition period or egg hatch in the present study (Fig. 2a). Whereas in our 


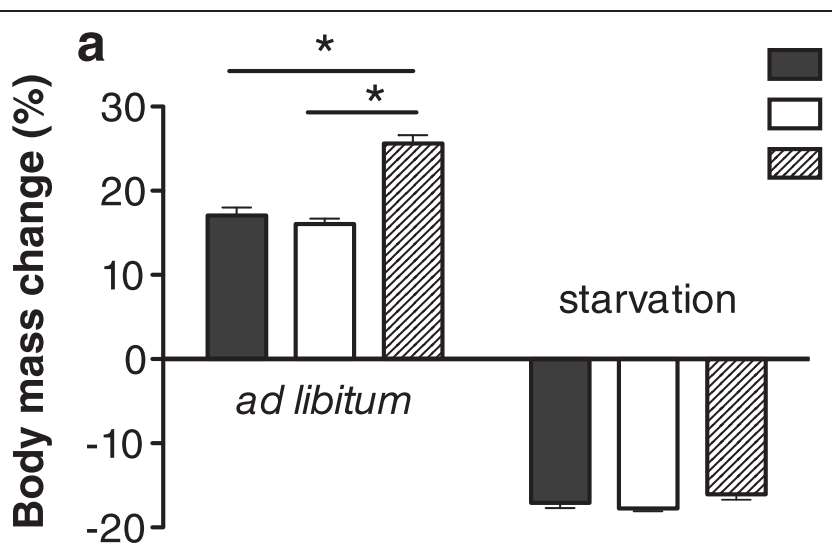

High

Variable

Restricted

Adult food regimes

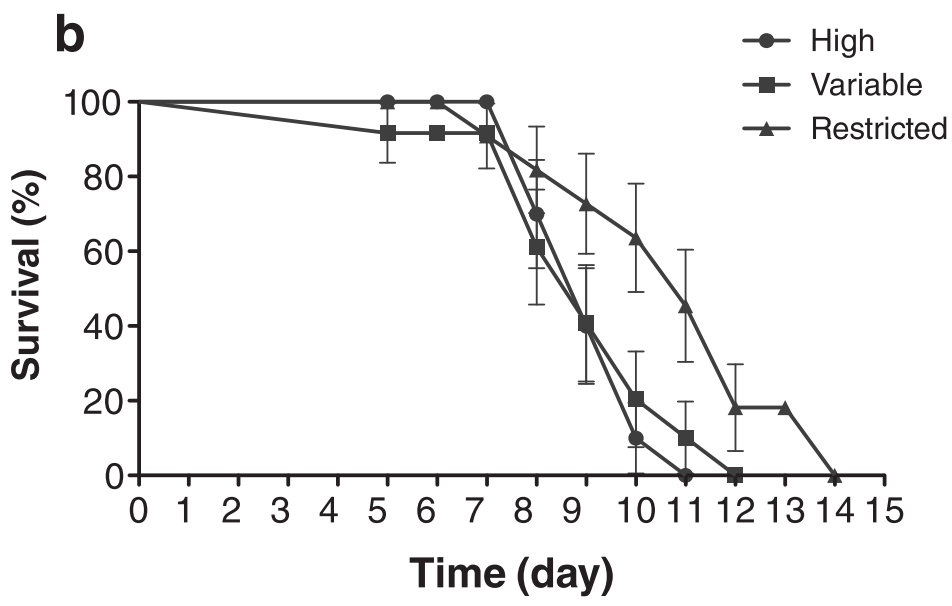

C

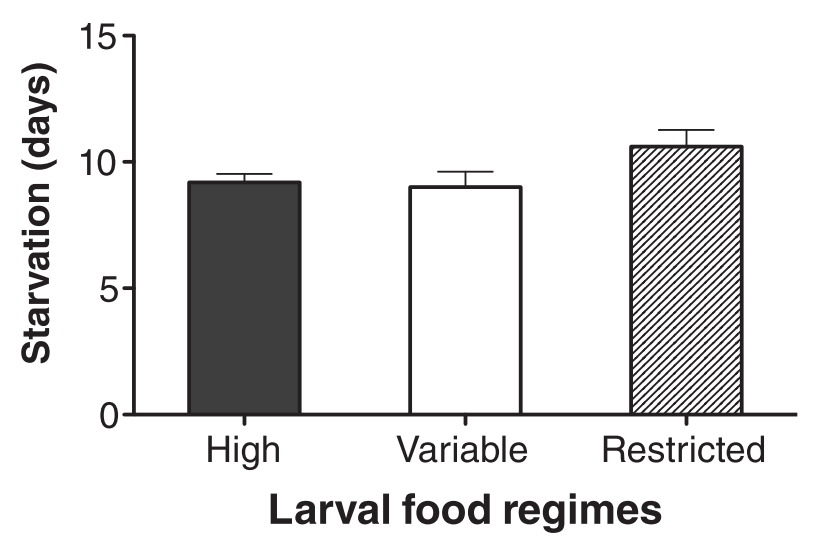

Fig. 3 Resistance of adult phynotypes resulting from high, variable and restricted larval food regimes to a 5-day starvation period in the adult stage. a Body mass changes after having experienced the starvation period versus ad libitum food in the early adult stage; $\mathbf{b}$, Survival curves of reproductively active adult phenotypes subjected to food starvation; $\mathbf{c}$, Mean survival time from the start of food deprivation to death. Error bars represent 1 SE value

study there was no statistical difference in starvation resistance between the resulting adult phenotypes of $C$. montrouzieri, previous studies did find that starvation is likely to trade-off with other fitness-related traits (e.g. fecundity and lifespan) [24, 41].
We also observed that adults which had experienced the variable food regime as larvae displayed lower expression levels of genes encoding immune enzymes (i.e. lysozyme, acid phosphatase and phenol oxidase) than did those from the high and restricted food regime, after 


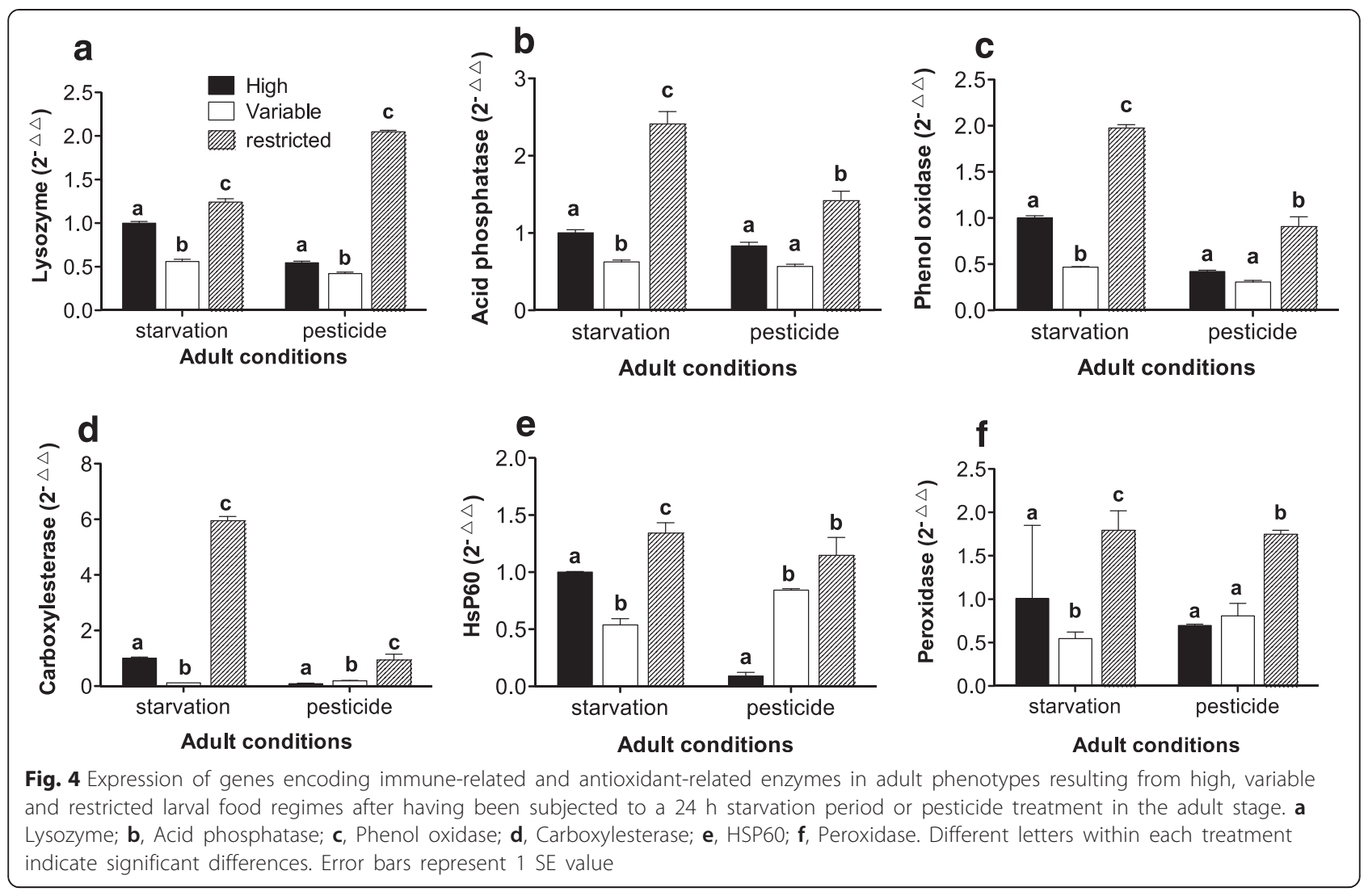

having experienced a short starvation period $(24 \mathrm{~h})$. Organismal immunity plays important roles in defending against harmful chemicals, pathogenic microorganisms, or parasites [42, 43]. Studies on Drosophila melanogaster have reported that the protein level of foods consumed by larvae may affect their immune activities [22]. Interestingly, the resulting phenotypes from the restricted larval food regime showed a higher gene expression of lysozyme, acid phosphatase and phenol oxidase (Fig. $4 \mathrm{a}, \mathrm{b}, \mathrm{c}$ ) than those undergoing the high and variable larval food regime under conditions of stress (i.e. starvation or exposure to an insecticide). This result indicates that the proportion of larval resources allocated to immunity may be independent of its effect on the organism's general condition (e.g., development and reproduction). That the expression level of immune genes can be affected by larval nutrition has also been reported in Drosophila melanogaster [22]. In the katydid, Kawanaphila nartee food availability has been noted to mediate the immune investment and reproductive efforts of females [44]. Generally, most resources will be first allocated to maintenance rather than reproduction and/or immune activities, especially under a food shortage condition [45].

The different phenotypes of $C$. montrouzieri resulting from larval feeding regimes also showed distinct antioxidant abilities as indicated by the expression of genes encoding antioxidant enzymes (i.e. peroxidase and HSP60), indicating different potentials of the nutritioninduced phenotypes in response to reactive oxygen species (ROS). ROS are the by-products of normal metabolic activities that may damage key biomolecules such as DNA, proteins and lipids [46]. Peroxidase and HSP60 play crucial roles in defending the organism against detrimental effects of the major ROS: superoxide anions and hydrogen peroxide [47]. As other two key antioxidant enzymes, SOD contributes to dismutating the superoxide anions into hydrogen peroxide and CAT further dismutates it into water [48].

Although developmental plasticity induced by nutritional conditions does not involve gene mutation or changes in DNA sequences, it is an important adaptive process in response to varying environmental conditions. The results of this and previous studies suggest that the developmental rate and body size of $C$. montrouzieri are largely dependent on larval food availability [21]. Arguably, many other factors (including temperature, humidity or photoperiod) may also exert impacts on its fitness and on the expression level of other genes encoding different functional proteins. The exact mechanisms and contributory factors involved in developmental plasticity are still not fully understood. Previous studies have noted that the organismal phenotypes result from the combination of external 
environment and gene inputs [1, 35]. The expected fitness of individuals who experience the developmental inputs and develop the phenotype should be higher than that of individuals who experience the developmental inputs but do not develop the phenotype [49]. External environment has been noted to affect the expression of genes by impacting on DNA methylation, protein modification and histone acetylation $[1,50]$. This process may shield genetic variation from natural selection, which presumably promotes the accumulation of cryptic variation that does not result in phenotypic variation even though having encountered genetic variation $[1,2]$.

\section{Conclusions}

C. montrouzieri may plastically respond to the variable nutritional conditions by altering its growth rate and allocation of resources, resulting in a variation of its body size and reproductive performance, as well as the expression of the immune- and antioxidant-related genes. Developmental plasticity is a crucial phenomenon, which is consequential for adaptability and diversity because the variation of individual phenotypes and resistance to stressful conditions may be associated with variation in developmental inputs in earlier larval life stages. This study provides further insight into the mechanisms of nutritioninduced plasticity in insects, but more detailed studies are warranted to explore the underlying mechanisms behind the different expression level of genes encoding immuneand antioxidant-related enzymes, and a further investigation is needed to examine whether the nutrition-induced phenotypes affect the fitness of future generations.

\section{Abbreviations \\ ANOVA: One-way analysis of variance; ROS: Reactive oxygen species; QPCR: Quantitative real-time PCR; SE: Standard error; HSP60: Heat shock protein 60; SOD: Superoxide dismutase; CAT: Catalase.}

\section{Competing interests}

The authors declare no competing interests.

\section{Authors' contributions}

XJQ conceived the study. XJQ, ZYH, PC, LHS together completed the experiments. XJQ analyzed the data and co-wrote the manuscript with PDC and $\mathrm{PH}$. All authors read, revised and approved the final version of the manuscript.

\section{Acknowledgements}

We thank Lijun Ma, Hanlun Liu, Xinyu Liang for assistance with the experiments. We also acknowledge Trudy Mackay, Tingting Zeng for critical comments and discussions on an earlier draft. This work was supported by grants from the National Basic Research Program of China (973 Program) (Grant NO. 2013CB127605), the National Natural Science Foundation of China (Grant NO. 31171899, 31572052) and the China Scholarship Council (CSC).

\section{Author details}

'State Key Laboratory of Biocontrol, Key Laboratory of Biodiversity Dynamics and Conservation of Guangdong Higher Education Institute, College of Ecology and Evolution, Sun Yat-sen University, Guangzhou 510275, China. 2Department of Crop Protection, Faculty of Bioscience Engineering, Ghent University, Ghent B-9000, Belgium. ${ }^{3}$ Guangdong Entomological Institute, Guangzhou 510260, China.
Received: 20 November 2015 Accepted: 25 November 2015

Published online: 08 December 2015

\section{References}

1. Beldade P, Mateus AR, Keller RA. Evolution and molecular mechanisms of adaptive developmental plasticity. Mol Ecol. 2011;20(7):1347-63. doi:10. 1111/j.1365-294X.2011.05016.x.

2. Monaghan P. Early growth conditions, phenotypic development and environmental change. Philos Trans R Soc Lond B. 2008;363(1497): 1635-45. doi:10.1098/rstb.2007.0011.

3. Uller T. Developmental plasticity and the evolution of parental effects. Trends Ecol Evol. 2008;23(8):432-8. doi:10.1016/j.tree.2008.04.005.

4. Dmitriew CM. The evolution of growth trajectories: what limits growth rate? Biol Rev. 2011;86(1):97-116. doi:10.1111/j.1469-185X.2010.00136.X.

5. Charmantier A, McCleery RH, Cole LR, Perrins C, Kruuk LEB, Sheldon BC. Adaptive phenotypic plasticity in response to climate change in a wild bird population. Science. 2008:320:800-3. doi:10.1126/science.1157174.

6. Scheiner SM. Genetics and evolution of phenotypic plasticity. Annu Rev Ecol Evol S. 1993;24:35-68. doi:10.1146/annurev.es.24.110193.000343.

7. Kotakorpi M, Tiainen J, Olin M, Lehtonen H, Nyberg K, Ruuhijärvi J, et al. Intensive fishing can mediate stronger size-dependent maternal effect in pike (Esox lucius). Hydrobiologia. 2013;718(1):109-18. doi:10.1007/s10750-013-1607-5.

8. Wang S, Michaud J, Zhang RZ, Zhang F, Liu S. Seasonal cycles of assortative mating and reproductive behaviour in polymorphic populations of Harmonia axyridis in China. Ecol Entomol. 2009;34(4): 483-94. doi:10.1111/j.1365-2311.2008.01075.x.

9. Braendle C, Davis GK, Brisson JA, Stern DL. Wing dimorphism in aphids. Heredity. 2006;97(3):192-9. doi:10.1038/sj.hdy.6800863.

10. Via S, Gomulkiewicz R, De Jong G, Scheiner SM, Schlichting CD, Van Tienderen $\mathrm{PH}$. Adaptive phenotypic plasticity: consensus and controversy. Trends Ecol Evol. 1995;10:212-7. doi:10.1016/S0169-5347(00)89061-8.

11. Moczek AP, Emlen DJ. Male horn dimorphism in the scarab beetle, Onthophagus taurus: do alternative reproductive tactics favour alternative phenotypes? Anim Behav. 2000;59(2):459-66. doi:10.1006/anbe.1999.1342.

12. Barchuk AR, Cristino AS, Kucharski R, Costa LF, Simoes ZL, Maleszka R. Molecular determinants of caste differentiation in the highly eusocial honeybee Apis mellifera. BMC Dev Biol. 2007;7:70. doi:10.1186/1471-213X-7-70.

13. Pigliucci M, Murren $C J$, Schlichting CD. Phenotypic plasticity and evolution by genetic assimilation. J Exp Biol. 2006;209(12):2362-7. doi:10.1242/jeb.02070.

14. Pilakouta N, Jamieson S, Moorad JA, Smiseth PT. Parental care buffers against inbreeding depression in burying beetles. Proc Natl Acad Sci U S A. 2015; 112(26):8031-5. doi:10.1073/pnas.1500658112.

15. Beldade P, Brakefield PM. The genetics and evo-devo of butterfly wing patterns. Nat Rev Genet. 2002;3(6):442-52. doi:10.1038/nrg818.

16. Pfennig DW, Wund MA, Snell-Rood EC, Cruickshank T, Schlichting CD, Moczek AP. Phenotypic plasticity's impacts on diversification and speciation. Trends Ecol Evol. 2010;25(8):459-67. doi:10.1016/j.tree.2010.05.006.

17. Moczek AP, Snell-Rood EC. The basis of bee-ing different- the role of gene silencing in plasticity. Evol Dev. 2008;10:511-3. doi:10.1111/j.1525-142X. 2008.00264.x

18. Kucharski R, Maleszka J, Foret S, Maleszka R. Nutritional control of ceproductive status in honeybees via DNA methylation. Science. 2008;319:1827-30. doi:10. 1126/science.1153069.

19. Frechin M, Stoeger T, Daetwyler S, Gehin C, Battich N, Damm EM, et al. Cell-intrinsic adaptation of lipid composition to local crowding drives social behaviour. Nature. 2015;523(7558):88-91. doi:10.1038/nature14429.

20. Xie J, De Clercq P, Zhang Y, Wu H, Pan C, Pang H. Nutrition-dependent phenotypes affect sexual selection in a ladybird. Sci Rep. 2015;5:13111. doi:10.1038/srep13111.

21. Xie J, Clercq P, Pan C, Li H, Zhang Y, Pang H. Physiological effects of compensatory growth during the larval stage of the ladybird, Cryptolaemus montrouzieri. J Insect Physiol. in press, 2015. doi:10.1016/j.jinsphys.2015.11.001.

22. Fellous S, Lazzaro BP. Larval food quality affects adult (but not larval) immune gene expression independent of effects on general condition. Mol Ecol. 2010;19(7):1462-8. doi:10.1111/j.1365-294X.2010.04567.x.

23. Auer SK, Arendt JD, Chandramouli R, Reznick DN. Juvenile compensatory growth has negative consequences for reproduction in Trinidadian guppies (Poecilia reticulata). Ecol Lett. 2010;13(8):998-1007. doi:10.1111/j.1461-0248.2010.01491.x.

24. Hodek I, Van Emden HF, Honěk A. Ecology and behaviour of the ladybird beetles (Coccinellidae). Oxford, UK: Blackwell Publishing Ltd; 2012. 
25. Wu HS, Zhang YH, Liu P, Xie JQ, He YY, Deng CS. Cryptolaemus montrouzierias a predator of the striped mealybug, Ferrisia virgata, reared on two hosts. J Appl Entomol. 2014;138(9):662-9. doi:10.1111/jen.12127.

26. Kairo M. Cryptolaemus montrouzieri (Mulsant) (Coccinellidae: Scymninae): a review of biology, ecology, and use in biological control with particular reference to potential impact on non-target organisms. CAB Rev. 2013, 8(005). doi:10.1079/pavsnnr20138005.

27. Zhang $Y H$, Jiang RX, Wu HS, Liu P, Xie JQ, He YY, et al. Next-generation sequencing-based transcriptome analysis of Cryptolaemus montrouzieri under insecticide stress reveals resistance-relevant genes in ladybirds. Genomics. 2012;100(1):35-41. doi:10.1016/j.ygeno.2012.05.002.

28. Limón-Pacheco J, Gonsebatt ME. The role of antioxidants and antioxidant-related enzymes in protective responses to environmentally induced oxidative stress. Mutat Res. 2009;674:137-47. doi:10.1016/j. mrgentox.2008.09.015

29. Jiang RX, Li S, Guo ZP, Pang H. The research status of Cryptolaemus montrouzieri Mulsant and establishing its description criteria. J Environ Entomol. 2009;31:238-47.

30. McGraw LA, Fiumera AC, Ramakrishnan M, Madhavarapu S, Clark AG, Wolfner MF. Larval rearing environment affects several post-copulatory traits in Drosophila melanogaster. Biol Lett. 2007;3(6):607-10. doi:10.1098/ rsbl.2007.0334

31. Stoks R, Cordoba-Aguilar A. Evolutionary ecology of Odonata: a complex life cycle perspective. Annu Rev Entom. 2012;57:249-65. doi:10. 1146/annurev-ento-120710-100557.

32. Dmitriew CM, Rowe $\mathrm{L}$. The effects of larval nutrition on reproductive performance in a food-limited adult environment. PLoS One. 2011;6(3): e17399. doi:10.1371/journal.pone.0017399.

33. DeWitt TJ, Sih A, Sloan-Wilson D. Costs and limits of phenotypic plasticity. Trends Ecol Evol. 1998;13:77-81. doi:10.1016/S0169-5347(97)01274-3.

34. Xie JQ, Zhang YH, Wu HS, Liu P, Deng CS, Pang H. Effects of mating patterns on reproductive performance and offspring fitness in Cryptolaemus montrouzieri. Entomol Exp App. 2014;153(1):20-3. doi:10.1111/eea.12224.

35. West-Eberhard MJ. Developmental plasticity and the origin of species differences. Proc Natl Acad Sci U S A. 2005;102(1):6543-9.

36. Sibly RM, Witt CC, Wright NA, Venditti C, Jetz W, Brown JH. Energetics, lifestyle, and reproduction in birds. Proc Natl Acad Sci U S A. 2012; 109(27):10937-41. doi:10.1073/pnas.0501844102.

37. Honěk A. Intraspecific variation in body size and fecundity in insects: a general relationship. Okios. 1993;66:483-92.

38. Berger D, Olofsson M, Friberg M, Karlsson B, Wiklund C, Gotthard K. Intraspecific variation in body size and the rate of reproduction in female insects: adaptive allometry or biophysical constraint? J Anim Ecol. 2012;81:1244-58. doi:10.1111/j.1365-2656.2012.02010.x

39. Wang S, Michaud JP, Tan XL, Zhang F. Comparative suitability of aphids, thrips and mites as prey for the flower bug Orius sauteri (Hemiptera: Anthocoridae). Eur J Entomol. 2014;111:221-6. doi:10. 14411/eje.2014.031

40. Roark AM, Bjorrndal KA. Bridging developmental boundaries: lifelong dietary patterns modulate life histories in a parthenogenetic insect. PloS One. 2014, 9:doi: 10.1371/journal.pone.0111654.

41. Rion S, Kawecki TJ. Evolutionary biology of starvation resistance: what we have learned from Drosophila. J Evol Biol. 2007;20:1655-64. doi:10. 1111/j.1420-9101.2007.01405.x.

42. Vilcinskas A. Evolutionary plasticity of insect immunity. J Insect Physiol. 2013; 59(2):123-9. doi:10.1016/j.jinsphys.2012.08.018.

43. James RR, Xu J. Mechanisms by which pesticides affect insect immunity. J Invertebr Pathol. 2012;109(2):175-82. doi:10.1016/j.jip.2011.12.005.

44. Vincent CM, Gwynne DT. Sex-biased immunity is driven by relative differences in reproductive investment. Proc R Soc B. 2014; 281(1790): doi:10.1098/rspb.2014.0333

45. Beaulieu M, Geiger RE, Reim E, Zielke L, Fischer K. Reproduction alters oxidative status when it is traded-off against longevity. Evolution. 2015; 69(7):1786-96. doi:10.1111/evo.12697.

46. Finkel T, Holbrook NJ. Oxidants, oxidative stress and the biology of ageing. Nature. 2000:408(6809):239-47. doi:10.1038/35041687.

47. Monaghan P, Metcalfe NB, Torres R. Oxidative stress as a mediator of life history trade-offs: mechanisms, measurements and interpretation. Ecol Lett. 2009;12(1):75-92. doi:10.1111/j.1461-0248.2008.01258.x.

48. De Block M, Stoks R. Compensatory growth and oxidative stress in a damselfly. Proc R Soc B. 2008;275:781-5. doi:10.1098/rspb.2007.1515.
49. Nettle D, Bateson M. Adaptive developmental plasticity: what is it, how can we recognize it and when can it evolve? Proc R Soc B. 2013;282:20151005. doi:10.1098/rspb.2015.1005

50. Watanabe S, Radman-Livaja M, Rando OJ, Peterson CL. A histone acetylation switch regulates $\mathrm{H} 2 \mathrm{~A}$.Z deposition by the SWR-C remodeling enzyme. Science. 2013;340:195-9. doi:10.1126/science.1229758.

\section{Submit your next manuscript to BioMed Central and we will help you at every step:}

- We accept pre-submission inquiries

- Our selector tool helps you to find the most relevant journal

- We provide round the clock customer support

- Convenient online submission

- Thorough peer review

- Inclusion in PubMed and all major indexing services

- Maximum visibility for your research

Submit your manuscript at www.biomedcentral.com/submit
(O) Biomed Central 